Available online on 15.12.2019 at http://jddtonline.info
Open Access to Pharmaceutical and Medical Research
unrestricted non-commercial use, provided the original work is properly cited

Open@ Access

Research Article

\title{
Estimation of Fibrinogen Level among Sudanese Patients with Myocardial Infraction
}

\author{
Mohammed AL Mustafa Ahmed Edres ${ }^{1}$, Nihad Elsadig Babiker ${ }^{1,2^{*}}$ \\ 1 Faculty of Medical Laboratory Sciences, National University, Sudan \\ 2 Darfur University College, Sudan
}

\begin{abstract}
Myocardial infraction (AMI) is an irreversible myocardial injury and necrosis caused by serious and long-term ischemia. It is generally seen in middle aged men with high risk factors for coronary artery disease. Only $4 \%$ of patients with AMI are under 40 years of age. This was a cross sectional study conducted at AL SHAB hospital, Khartoum, Sudan, aimed to estimate the fibrinogen level among Sudanese patients with myocardial infraction. 50 patients attending Alshab Hospital and diagnosed with MI used as a case group and 50 apparently healthy individuals with no history of MI were selected as control group. $1.8 \mathrm{ml}$ of blood samples has been collected in sodium citrate anticoagulant container for measurement of fibrinogen level by clauss method in coagulometer device. It is clearly significant increase in fibrinogen level in myocardial infraction patient (p.value 0.000). In addition, the prothrombin time and gender were insignificantly differences in (AMI) patients. In the other hand, age and smoking significantly increased as risk factor in myocardial infraction. This study concluded that fibrinogen level was significantly increased in Sudanese patients with myocardial infraction.
\end{abstract}

Keywords: Myochardial Infraction, Fibrinogen, Prothrombin Time, Coagulometer

Article Info: Received 05 Oct 2019; Review Completed 16 Nov 2019; $\quad$ Accepted 21 Nov 2019; Available online 15 Dec 2019

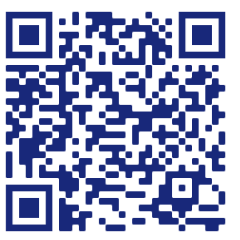

Cite this article as:

Edres NAMA, Babiker NE, Estimation of Fibrinogen Level among Sudanese Patients with Myocardial Infraction, Journal of Drug Delivery and Therapeutics. 2019; 9(6-s):21-27 http://dx.doi.org/10.22270/jddt.v9i6-s.3737

*Address for Correspondence:

Nihad Elsadig Babiker, Faculty of Medical Laboratory Sciences, National University, Sudan

\section{INTRODUCTION}

Acute myocardial infarction (AMI) is an irreversible myocardial injury and necrosis caused by serious and longterm ischemia. It is generally seen in middle aged men with high risk factors for coronary artery disease. Only 4\% of patients with AMI are under 40 years of age. Coronary anatomy is normal in $30 \%$ of young AMI patients. The presence of normal coronary anatomy is related to coronary vasospasm, embolism from endocardium or heart vessels and platelet aggregation or spontaneous lysis of thrombus.[1]

The morbidity and mortality rates of ACS are increasing, thus, Premature myocardial infarction with life threatening complications may become epidemic in some Asian and African countries Deaths per 1000 person-years in the quartile (P,0.001 for trend). [2].

\section{Pathogenicity}

Instability of coronary atherosclerosis plaque, which is easily to rupture that, may induce platelet aggregation and lead to complete or incomplete coronary artery embolism. Further causes severe lumen stenosis and myocardial blood supply shortage. At present, the treatment principle of ACS is early detection, early diagnosis and early treatment to achieve revascularization. In recent years, with the development in Chest Pain Center and interventional technology, ACS patients can receive timely treatment. However, research has found that some ACS patients would still develop major adverse cardiovascular events (MACEs) even after getting through the acute phase; MACEs can cause serious threats to the quality of life and even lead to death of patients. Therefore, predicting the short term prognosis for ACS patients is one of the hot issues that draw clinical attention. The pathological basis of ACS is thrombosis caused by abnormal fibrinolysis and blood coagulation and the pathological basis of MACE is the formation of sub-acute or chronic coronary embolism. In recent years, the researches confirmed that there was a correlation between the prognosis of patients with ACS and diverse biochemical markers. Its immunocompetence fragment can reflect the plasma concentration of cross linked fibrin polymer and its plasma level can effectively and specifically reflect the increase in blood circulating coagulation and the level of secondary fibrinolytic hyperactivity [3]. 
AMI is diagnosed where there are at least two of following; chest pain longer than 30 minutes which does not respond to nitrates, in 12-lead electrocardiography, a new $Q$ wave longer than $40 \mathrm{~ms}$ and/or ST segment elevation $0.1 \mathrm{mV}$ on at least two extremity derivations or $0.2 \mathrm{mV}$ on precordial derivation, a 1.5 times, or higher, increase in serum creatinphosphokinase-MB and TT, Fibrinogen well elevated.[3]

\section{Fibrinogen level}

Fibrinogen is one of 13 coagulation factors responsible for normal blood clotting and made in the liver, also known as factor $1^{[4]}$. When bleeding start the body initiates process called coagulation cascade or clotting cascade, this process cause coagulation factor to combine and produce a clot that will stop the bleeding. If the body hasn't enough fibrinogen or if the cascade isn't working normally clots will have difficulty forming, this can cause excessive bleeding. [5]

Low fibrinogen levels can also cause thrombosis in coagulation activity. Thrombosis refers to the formation of blood clot inside of blood vessel. The clot blocks normal blood flow through the circulatory system. This can lead to serious medical condition such as heart attack and stroke [6], Numerous prospective epidemiological studies have reported positive associations between the risk of coronary heart disease (CHD) and plasma fibrinogen levels. [7]. Fibrinogen levels decreased considerably by lifestyle interventions that also affect levels of risk factors such as regular exercise, smoking discontinuation and moderate alcohol consumption, the measurement of fibrinogen level may help in disease prediction or prevention. [8] This study aimed to estimate the fibrinogen level among Sudanese patients with myocardial infraction.

\section{MATERIALS AND METHODS}

This is a cross sectional study, conducted at Alshab Hospital, Khartoum, Sudan during the period May 2019 to July 2019. All patients attending Alshab Hospital and diagnosed with MI during the aforementioned period were included. In addition to that, apparently healthy individuals with no history of MI were selected as control group. The study was approved by the ethical committee of $\mathrm{Al}$ shab Hospital, The data was collected using pre-designed structural questionnaire, the demographic and clinical data concerning each participant was obtained from the registry data base office, which included the following information: (Gender, age, weight, smoking, chronic disease, treatment, exercise and medical history). The laboratory data included hematological results and fibrinogen level findings. $2.8 \mathrm{ml}$ of blood samples were collected in trisodium citrate anticoagulant container for fibrinogen level count.

\section{Tests procedure}

\section{Thrombin time}

$75 \mu \mathrm{l}$ of thrombin solution added to $100 \mu \mathrm{l}$ of tested plasma in cuvette at $37^{\circ} \mathrm{C}$ and start reading of clotting time.

Sample diluted in 1:10 in imidazole buffer

Normal range: up to 10_12 second.

\section{2. prothrombin time}

$100 \mu \mathrm{l}$ of thrombin solution was added to $100 \mu \mathrm{l}$ of tested plasma in cuvette at $37^{\circ} \mathrm{C}$ and reading of clotting time was recorded.
Normal range: up to $11 \_13.5$ second.

\section{3 .Fibrinogen assay}

The preparation of calibration/standard plasma dilution in Imidazole buffer was followed; 1:5(200\%)-1:10(100\%)1:20(50\%)-1:30(33\%)-1:40(25\%). Firstly $0.1 \mathrm{ml}$ of each dilution was incubated at $37 \mathrm{C}$ for 120 seconds, then $0.075 \mathrm{ml}$ of thrombin solution was added and simultaneously start reading, the clot was observed and clot time was measured nearest to 0.1 seconds. The polt calibration curve on log- log graph paper and the clot time versus the fibrinogen concentration in $\mathrm{g} / \mathrm{l}$ the curve was obtained by the linear. The dilute control plasma or patient sample 1:10 in Imidazole buffer. The normal reference for fibrinogen is generally $1.5-3.5 \mathrm{~g} / \mathrm{l}(150-350 \mathrm{mg} / \mathrm{dl})$

\section{RESULTS}

In the present study 50 of myocardial infraction patients were included. Among them, 35 were males, while 15 were females. In addition, 50 of apparently healthy individuals were selected as control group, 19 were males, while 31 were female. (fig 1). The most affected age group in the patients was more than 60 years followed by $51-60$ years which constituted $52 \%$ and $26 \%$, respectively (Table 1).

The hematological parameters revealed that, when compared the age group with thrombin time and fibrinogen level among the patient gave significant result $(\mathrm{P}=0.000)$ (table 5). Also, there was insignificant result when Comparison of age $(p=0.866)$, Weight $(p=0.520)$, PT $(p=$ $0.617)$, INR ( $p=0.422$ ) (table 6), but significant in TT ( $p=$ $0.002)$ and Fibrinogen level $(p=0.008)$ among gender of MI patients (table 6). When Comparison of PT $(\mathrm{p}=0.229)$, INR $(p=0.422)$, TT $(p=0.159)$ and Fibrinogen level $(p=0.146)$ among patients used treatment of chronic disease (diabetes and hypertension) there was insignificant result (table7). Also when Comparison of PT $(p=0.068)$, INR ( $p=0.134)$ among smoker gave insignificant result, while the TT ( $p=$ $0.000)$, and Fibrinogen level $(p=0.000)$ among smoker patients gave significant result (table 8). While, there was significant difference when correlation between weight and TT (second). In addition to that, there was significant difference between weight and fibrinogen levels ( $\mathrm{mg} / \mathrm{dl}$ ).

Table (1): Age groups of affected patients

\begin{tabular}{|l|c|c|}
\hline Age groups & frequency & Percent \\
\hline Less than 30 & 2 & 4.0 \\
\hline $\mathbf{3 1 - 4 0}$ & 1 & 2.0 \\
\hline $\mathbf{4 1 - 5 0}$ & 8 & 16.0 \\
\hline $\mathbf{5 1 - 6 0}$ & 13 & 26.0 \\
\hline More than 60 & 26 & 25.0 \\
\hline Total & 50 & 100.0 \\
\hline
\end{tabular}

Table (2): Frequency of smoking among affected patients

\begin{tabular}{|l|c|c|}
\hline Smoking & Frequency & Percent \\
\hline NO & 33 & 66.0 \\
\hline Yes & 17 & 34.0 \\
\hline Total & 50 & 100.0 \\
\hline
\end{tabular}


Table (3): Descriptive statistics for myocardial infarction patients

\begin{tabular}{|l|c|c|c|c|c|}
\hline Variable & N & Minimum & Maximum & Mean & Std. Deviation \\
\hline Age (years) & 50 & 20 & 90 & 61.5 & 14.2 \\
\hline Weight (kg) & 50 & 47 & 90 & 74.9 & 7.9 \\
\hline PT (seconds) & 50 & 13.7 & 19.8 & 16.4 & 1.3 \\
\hline INR & 50 & 0.9 & 1.4 & 1.1 & 0.13 \\
\hline TT (seconds) & 50 & 17.5 & 25.0 & 20.9 & 2.2 \\
\hline Fibrinogen (mg/dl) & 50 & 421 & 602 & 505.1 & 53.2 \\
\hline
\end{tabular}

Table (4): Descriptive statistics for control

\begin{tabular}{|l|c|c|c|c|c|}
\hline & N & Minimum & Maximum & Mean & Std. Deviation \\
\hline Age (years) & 50 & 22 & 36 & 28.9 & 3.9 \\
\hline TT (seconds) & 50 & 9.9 & 12.0 & 10.7 & 0.7 \\
\hline Fibrinogen (mg/dl) & 50 & 238 & 290 & 260.3 & 15.8 \\
\hline
\end{tabular}

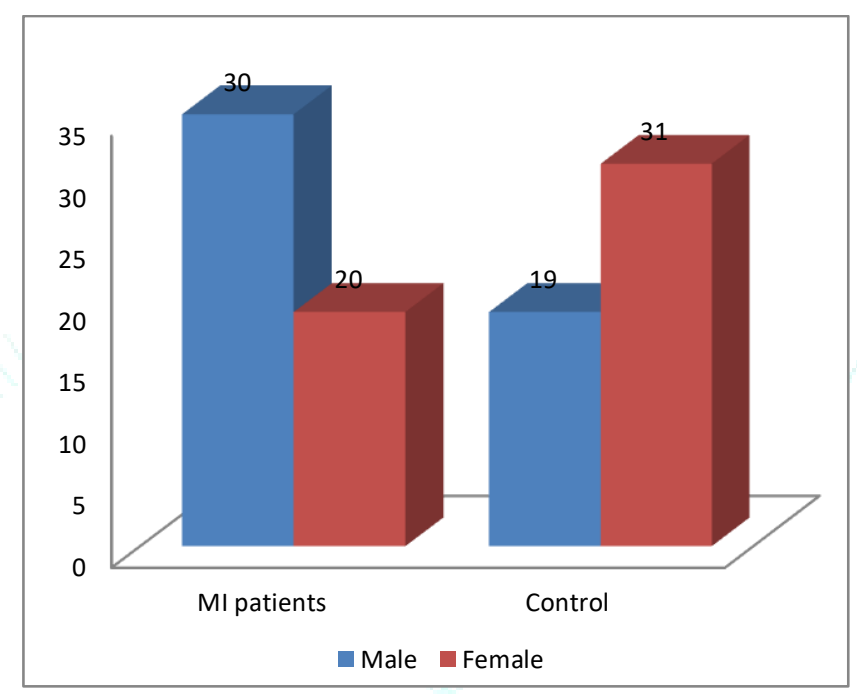

Fig (1): Frequency of gender among study population

Table (5): Comparison of age, TT and Fibrinogen level among population study

\begin{tabular}{|l|c|c|c|}
\hline \multicolumn{1}{|c|}{ Parameters } & \multicolumn{2}{c|}{$\begin{array}{c}\text { Population study } \\
\text { (Mean } \pm \text { SD) }\end{array}$} \\
\cline { 2 - 4 } & MI patients (n=50) & $28.9 \pm 3.9$ \\
\hline Age (years) & $61.5 \pm 14.2$ & $10.7 \pm 0.7$ \\
\hline TT (seconds) & $20.9 \pm 2.2$ & 0.000 \\
\hline Fibrinogen (mg/d) & $505.1 \pm 53.2$ & $260.3 \pm 15.8$ \\
\hline
\end{tabular}

Table (6): Comparison of age, Weight, PT, INR, TT and Fibrinogen level among gender of MI patients

\begin{tabular}{|l|c|c|}
\hline \multicolumn{1}{|c|}{ Parameters } & Male (n=35) & $\begin{array}{c}\text { Gender } \\
\text { (Mean } \pm \text { SD) }\end{array}$ \\
\cline { 2 - 3 } & $61.3 \pm 14.5$ & 0.866 \\
\hline Age (years) & $74.3 \pm 6.3$ & 0.520 \\
\hline Weight (kg) & $16.5 \pm 1.3$ & $76.3 \pm 11.1$ \\
\hline PT (seconds) & $1.1 \pm 0.13$ & $16.2 \pm 1.6$ \\
\hline INR & $21.5 \pm 2.2$ & $1.1 \pm 0.15$ \\
\hline TT (seconds) & 0.422 \\
\hline Fibrinogen (mg/dl) & $517.8 \pm 52.8$ & $19.7 \pm 1.6$ \\
\hline
\end{tabular}


Table (7): Comparison of PT, INR, TT and Fibrinogen level among patients use treatment of chronic disease

\begin{tabular}{|l|c|c|c|}
\hline \multirow{2}{*}{ Parameters } & \multicolumn{2}{|c|}{$\begin{array}{c}\text { Treatment } \\
\text { (Mean } \pm \text { SD) }\end{array}$} & P. value \\
\cline { 2 - 4 } & No (n=35) & Yes (n=15) \\
\hline PT (seconds) & $16.2 \pm 1.4$ & $16.7 \pm 1.2$ & 0.229 \\
\hline INR & $1.1 \pm 0.1$ & $1.1 \pm 0.1$ & 0.422 \\
\hline TT (seconds) & $21.3 \pm 2.2$ & $20.3 \pm 1.9$ & 0.159 \\
\hline Fibrinogen (mg/dl) & $512.3 \pm 54.4$ & $488.3 \pm 48.1$ & 0.146 \\
\hline
\end{tabular}

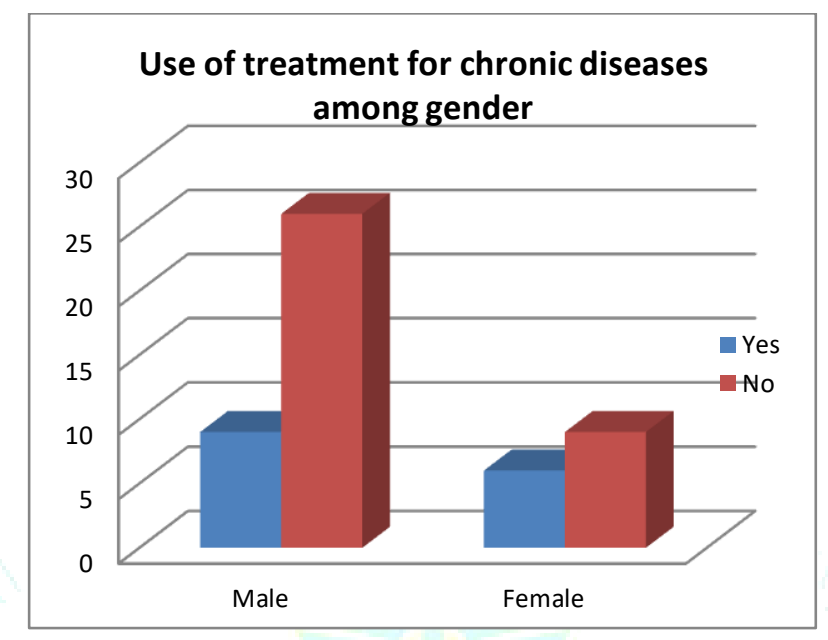

Fig (2): Frequency of use treatment for chronic diseases among gender

Table (8): Comparison of PT, INR, TT and Fibrinogen level among smoker

\begin{tabular}{|l|c|c|c|}
\hline \multirow{2}{*}{ Parameters } & \multicolumn{2}{|c|}{$\begin{array}{c}\text { Smoking } \\
\text { (Mean } \pm \text { SD) }\end{array}$} & \multirow{2}{*}{ P. value } \\
\cline { 2 - 4 } & No (n=33) & Yes (n=17) & \\
\hline PT (seconds) & $16.1 \pm 1.3$ & $16.9 \pm 1.3$ & 0.068 \\
\hline INR & $1.1 \pm 0.12$ & $1.1 \pm 0.13$ & 0.134 \\
\hline Fibrinogen (mg/dl) & $20.0 \pm 1.7$ & $22.7 \pm 1.9$ & 0.000 \\
\hline
\end{tabular}

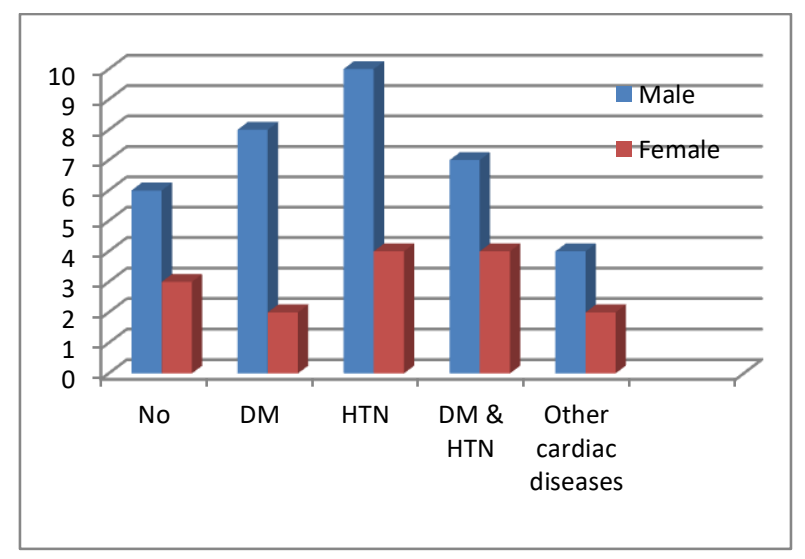

Fig (3): frequency of chronic diseases among gender 
Table (9): Multiple Comparisons TT and Fibrinogen level according to risk factor of other diseases

\begin{tabular}{|c|c|c|c|c|c|}
\hline Parameters & Sample (I) & Sample (II) & Mean of (I) & Mean of (II) & $P$ value \\
\hline \multirow[t]{9}{*}{ TT (sec) } & No & DM & $22.9 \pm 1.9$ & $20.3 \pm 2.3$ & $0.007^{*}$ \\
\hline & No & DM \& HTN & $22.9 \pm 1.9$ & $20.2 \pm 1.6$ & $0.003^{*}$ \\
\hline & No & HTN & $22.9 \pm 1.9$ & $20.9 \pm 2.2$ & $0.020 *$ \\
\hline & No & Other cardiac disease & $22.9 \pm 1.9$ & $20.9 \pm 1.9$ & 0.066 \\
\hline & DM & DM \& HTN & $20.3 \pm 2.3$ & $20.2 \pm 1.6$ & 0.838 \\
\hline & DM & HTN & $20.3 \pm 2.3$ & $20.9 \pm 2.2$ & 0.515 \\
\hline & DM & Other cardiac disease & $20.3 \pm 2.3$ & $20.9 \pm 1.9$ & 0.548 \\
\hline & HTN & DM \& HTN & $20.9 \pm 2.2$ & $20.2 \pm 1.6$ & 0.374 \\
\hline & HTN & Other cardiac disease & $20.9 \pm 2.2$ & $20.9 \pm 1.9$ & 0.933 \\
\hline \multirow{9}{*}{$\begin{array}{l}\text { Fibrinogen } \\
\text { (mg/dl) }\end{array}$} & No & DM & $555.3 \pm 49.2$ & $488.7 \pm 55.4$ & $0.005^{*}$ \\
\hline & No & DM \& HTN & $555.3 \pm 49.2$ & $484.4 \pm 38.3$ & $0.002 *$ \\
\hline & No & HTN & $555.3 \pm 49.2$ & $501.0 \pm 53.4$ & $0.013^{*}$ \\
\hline & No & Other cardiac disease & $555.3 \pm 49.2$ & $504.3 \pm 44.2$ & 0.055 \\
\hline & $\mathrm{DM}$ & DM \& HTN & $488.7 \pm 55.4$ & $484.4 \pm 38.3$ & 0.841 \\
\hline & DM & HTN & $488.7 \pm 55.4$ & $501.0 \pm 53.4$ & 0.548 \\
\hline & DM & Other cardiac disease & $488.7 \pm 55.4$ & $504.3 \pm 44.2$ & 0.541 \\
\hline & HTN & DM \& HTN & $501.0 \pm 53.4$ & $484.4 \pm 38.3$ & 0.405 \\
\hline & HTN & Other cardiac disease & $501.0 \pm 53.4$ & $504.3 \pm 44.2$ & 0.890 \\
\hline
\end{tabular}

* The mean difference is significant at the 0.05 level.

Table (10): Comparison of PT, INR, TT and Fibrinogen level according to Exercise

\begin{tabular}{|l|c|c|c|}
\hline \multirow{2}{*}{ Parameters } & \multicolumn{2}{c|}{ Exercise (Mean \pm SD) } & \multirow{2}{*}{ P. value } \\
\cline { 2 - 4 } & No $(\mathbf{n = 3 8 )}$ & Yes (n=12) & \\
\hline PT (seconds) & $16.4 \pm 1.4$ & $16.2 \pm 1.1$ & 0.623 \\
\hline INR & $1.1 \pm 0.1$ & $1.1 \pm 0.1$ & 0.658 \\
\hline TT (seconds) & $21.1 \pm 2.2$ & $20.4 \pm 2.2$ & 0.336 \\
\hline Fibrinogen (mg/dl) & $508.6 \pm 52.5$ & $493.8 \pm 56.2$ & 0.408 \\
\hline
\end{tabular}

Table (11): Correlations between Weight and TT

\begin{tabular}{|l|l|c|c|}
\hline \multicolumn{3}{|c|}{ Correlations } \\
\hline \multirow{3}{*}{ Weight } & Pearson Correlation & Weight & TT \\
\cline { 2 - 4 } & Sig. (2-tailed) & 1 & -.063 \\
\cline { 2 - 4 } & $\mathrm{N}$ & 50 & .663 \\
\hline \multirow{3}{*}{ TT } & Pearson Correlation & -.063 & 50 \\
\cline { 2 - 4 } & Sig. (2-tailed) & .663 & 1 \\
\cline { 2 - 4 } & $\mathrm{N}$ & 50 & 50 \\
\hline
\end{tabular}

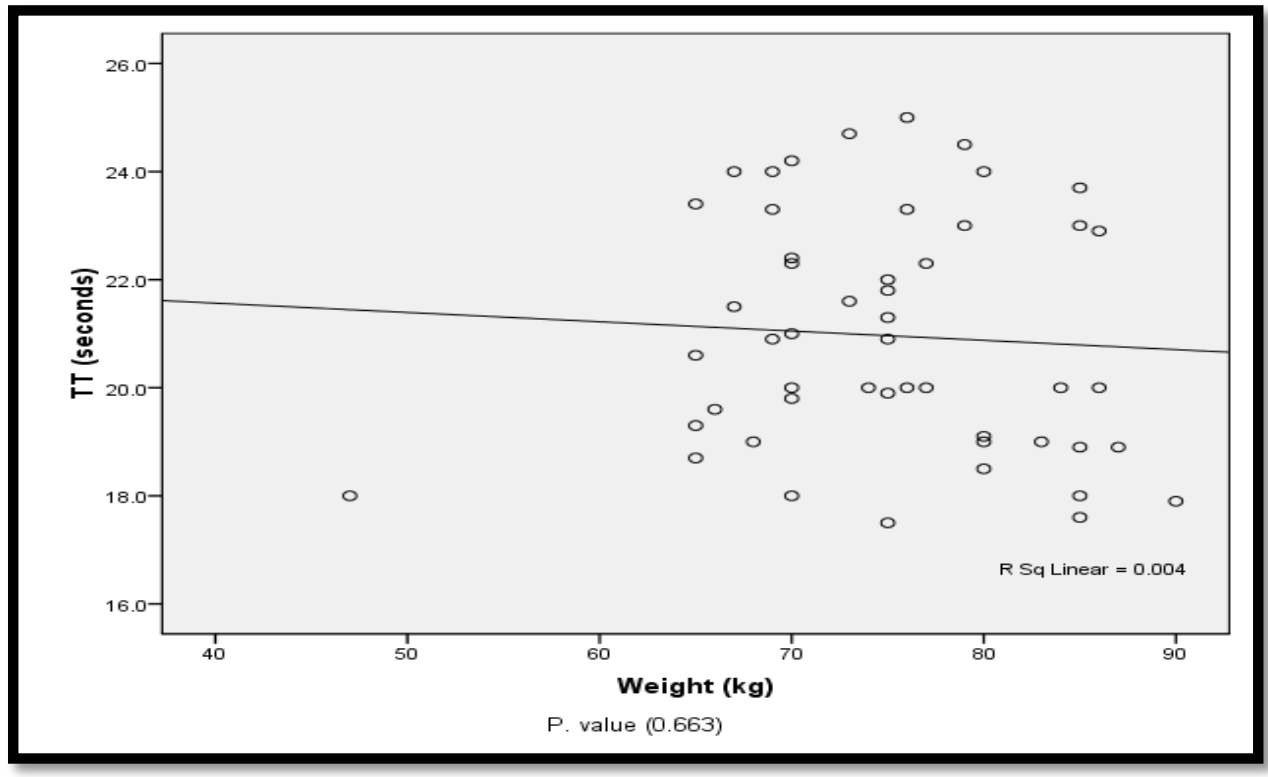

Fig (4): Correlations between Weight and TT 
Table (12): Correlations between Weight and Fibrinogen level

\begin{tabular}{|l|l|r|r|}
\hline \multicolumn{3}{|c|}{ Correlations } \\
\hline \multirow{3}{*}{ Weight } & Pearson Correlation & \multicolumn{1}{|c|}{ Weight } & Fibrinogen \\
\cline { 2 - 4 } & Sig. (2-tailed) & 1 & -.053 \\
\cline { 2 - 4 } & $\mathrm{N}$ & 50 & .716 \\
\hline \multirow{3}{*}{ Fibrinogen } & Pearson Correlation & -.053 & 50 \\
\cline { 2 - 4 } & Sig. (2-tailed) & .716 & 1 \\
\cline { 2 - 4 } & $\mathrm{N}$ & 50 & 50 \\
\hline
\end{tabular}

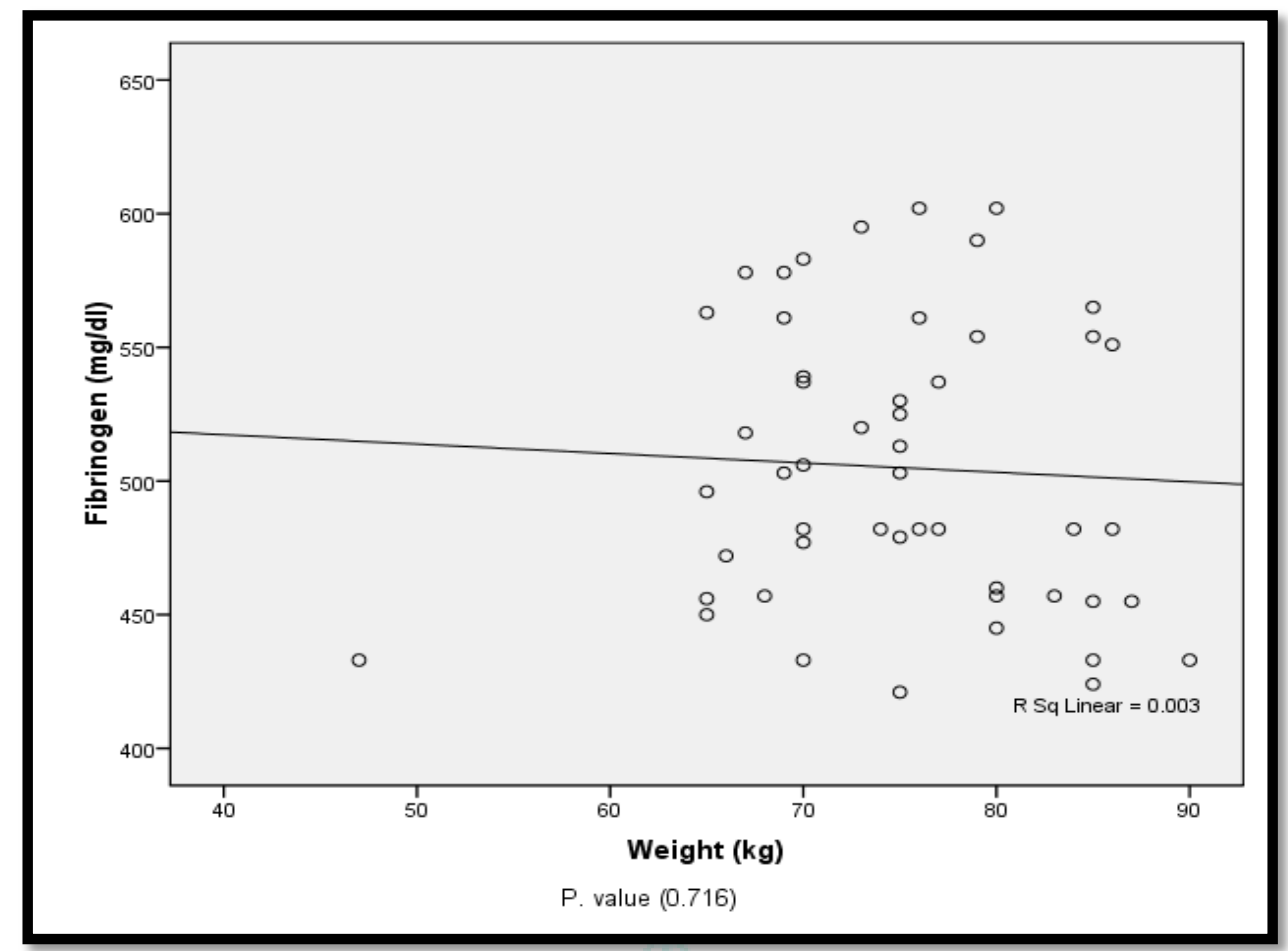

Fig (5): Correlations between Weight and Fibrinogen level

\section{DISCUSSION}

In the present study the results revealed the following: The descriptive statistics for myocardial infarction patients; mean of age (years) 61.5 and (Std deviation 14.2), mean of weight $(\mathrm{kg}) 74.9$ (std deviation 7.9), mean of PT (second) 16.4 (std deviation 1.3), mean of INR 1.1 (std deviation 0.13 ), mean of TT (second) 20.9 (std deviation 2.2) and mean of fibrinogen (mg/dl) 505.(std deviation53.2). Also, the Descriptive Statistics for control; mean of age (years) 28.9 (std deviation 3.9), TT (second) 10.7 (std deviation 0.7) and mean of fibrinogen (mg/dl) 260.3 (std deviation15.8). The frequency of gender among study population; for the patients the males more than females, while in the control the females more than males.

There was significant difference of age (years) in myocardial infarction patients when compared with control group (mean 61.5 \pm Sd) (p.value 0.000) and the most affected age group above 60 , that is consistent with other study which reported; acute myocardial infarction is generally caused by thrombus arising secondary to the rupture of the atherosclerotic plaque in coronary artery and usually affects adults over 40 . Only $4 \%$ of AMI patients are under 40 . [9,10] Also, there was significant difference of TT (second) in myocardial infraction patients when compared with control group (mean 20.9 \pm SD) (p.value 0.000), that is agree with other study also showed a significant difference of thrombin time in patients with acute phase of MI. [11] Regarding the fibrinogen level our results showed; there was a significant difference of fibrinogen $(\mathrm{mg} / \mathrm{dl})$ in myocardial infraction patients when compared with control group (p.value 0.000), that is consistent with other study also reported that; the serum fibrinogen levels are a risk factor for premature AMI.[12,13] In the present study there was insignificant difference of age (years) in gender of myocardial infarction patients male when compared with female (p.value0.866). One of previous study agreed with our finding and reported that; the decline among women to be less consistent than that observed in men. [14] Also, there was insignificant difference of weight $(\mathrm{kg})$ in gender of myocardial infraction male (mean 74.3 \pm SD) when compared with female (mean $76.3 \pm$ SD) (p.value 0.520). In compare with other study said that; overweight is often regarded as one of the most important modifiable cardiovascular risk factors, but its association with cardiovascular health over a lifespan remains incompletely understood. Not all studies have demonstrated adverse effects of overweight. [15]

There was insignificant difference of PT (second) and INR in gender of myocardial infraction male when compared with female (p.value 0.617) (p.value 0.422). That is agreed with other study which reported that; prothrombin time (PT) and activated partial thromboplastin time(a PTT) didn't show any significance among patients with AMI and disagreed with other study showed; both PT and a PTT are significantly increased in AMI patients on anticoagulation therapy. [16,17] Also, there was insignificant difference of PT (second) and INR in myocardial infraction patients not used 
treatment for the chronic disease when compared with other used treatment (p.value0.229) (p.value0.422). In addition to that; there was insignificant difference of PT (second) and INR in myocardial infraction patient who didn't smoke when compared with smoking patients (p.value0.068). In the other hands our results revealed that; there was significant difference of fibrinogen levels $(\mathrm{mg} / \mathrm{dl})$ and TT (second) in myocardial infraction male when compared with female ( $\mathrm{p}$. value 0.00$) \&(p$. value 0.002 ). Also, there was insignificant difference of fibrinogen levels (mg/dl) and TT (second) in myocardial infraction patients that didn't use treatment when compared with used treatment (p.value0.159) \& (p.value0.146) Indeed, the frequency of use treatment for chronic diseases among gender of study population; male didn't use treatment more than female. There was significant difference of fibrinogen levels $(\mathrm{mg} / \mathrm{dl})$ and TT (second) in myocardial infraction patients who did not smoke when compared with smoking patients (p.value0.000). Many studies confirmed that; Smoking is the most important and commonest risk factor in young patients. $[18,19]$

In the present study the frequency of chronic diseases (hypertension, diabetes mellites and cardiac disease) among gender; male are more than the female in the study population, also there was significant difference for TT when compared patients of myocardial infraction with no risk factor (chronic diseases) with the patient with chronic diseases (DM P.V 0.007, HT P.V 0.003), while there was insignificant results when compered the two groups in the patients with the cardiac diseases

For the fibrinogen levels there was a significant difference when compered between the patients with chronic disease with the patients without chronic diseases ( $p$ value 0.002 for DM and $p$ value 0.013 for HT) and in significant difference in the patient with cardic disease (p.value0.066). Many studies agreed with our results and revealed the same risk factors for AMI including age, smoking, cholesterol, physical inactivity, arterial hypertension, diabetes. $[18,20,21]$

Finally there was insignificant difference of PT (second), INR, TT (second) and fibrinogen levels $(\mathrm{mg} / \mathrm{dl}$ ) when compered between the patients that were made exercise and the other were not. also, there was significant difference when correlation between weight and TT and fibrinogen levels that is in agreed with other study revealed that; both overweight and obesity increased the incidence of AMI [22], another study showed that; an independent relationship between them. [23]

\section{CONCLUSIONS}

Fibrinogen level was significantly increased in myocardial infarction patients, also here were significant differences related to age group, smoking and weight, however PT, INR insignificantly increased in myocardial infarction patient and there were insignificant differences related to exercise.

\section{REFERENCES}

1. Lamm G. The epidemiology of acute myocardial infarction inyoung age groups. In: Roskamm H ed. Myocardial infarction at young age. Springer-Verlag, Berlin 1981: 5-7.

2. Wilhelmsen L, Svärsudd K, Korsan-Bengtsen K, Larsson B, Welin L,Tibblin G. Fibrinogen as a risk factor for stroke and myocardial infarction. N Engl J Med. 1984; 311:501-505.

3. Ernst E, Koenig W, Lowe GDO, Meade TW, eds. Fibrinogen: A "New" Cardiovascular Risk Factor. Vienna, Austria: BlackwellMZW; 1992.
4. Gabay C, Kushner I. Acute-phase proteins and other systemic responsesto inflammation. N Engl J Med. 1999; 340:448-454.

5. Lowe GDO. Blood rheology, haemostasis and vascular disease. In: Bloom AL, Forbes CD, Thomas DP, Tuddenham EGD, eds. Haemostasis and Thrombosis. 3rd ed. Edinburgh, UK: Churchill Livingstone; 1994: 1169-1188.

6. Ernst E, Resch K. L. Fibrinogen as a cardiovascular risk factor: Ameta-analysis and review of the literature. Ann Intern Med. 1993;118: 956-963.

7. Ridker PM, Cushman M, Stampfer MJ, Tracy RP, Hennekens $\mathrm{CH}$. Inflammation, aspirin, and the risk of cardiovascular disease in apparently healthy men. N Engl J Med. 1997; 336:973-979.

8. Trell E. Community-based preventive medical department for individualrisk factor assessment and intervention in an urban population Prev Med. 1983; 2:397-402.

9. Ersan Tatli, Fatih Ozcelik, Meryem Aktoz . plasma fibrinogen level may predict critical coronary artery stenosis in young adults with myocardial infarction. Cardiology journal 2009; 318.

10. Lamm G. The epidemiology of acute myocardial infarction inyoung age groups. In: Roskamm H ed. Myocardial infarction at young age. Springer-Verlag, Berlin 1981: 5-7.

11. Elif Elmas, Thorstenkaelsch, Christianwolpert. Markers of thrombin formation are transiently increased in patients with VF during the acute phase of MI. Clin. Cardiol 2006; (29): 165169.

12. Mohammad Shojaie,Morteza Pourahmad ,Ahad eshraghian ,Hamid Reza izadi ,Farzan naghshvar. Fibrinogen as a risk factor for premature myocardial infarction in iranian patients. Vascular Health and Risk Management 2009; 5:674.

13. Ersan Tatli, Fatih Ozcelik, Meryem Aktoz . Plasma fibrinogen level may predict critical coronary artery stenosis in young adults with myocardial infarction. Cardiology journal 2009; 318

14. Wayne D. Rosamond, Thomas H. Mosley. Twenty-Two Year Trends in Incidence of Myocardial Infarction, CHD Mortality, and Case-Fatality in Four US Communities, 1987 to 2008. PMC 2013, (17):10.

15. Hamer M, Stamatakis E. Metabolically healthy obesity and risk of allcause and cardiovascular disease mortality. J Clin Endocrinol Metab 2012; 97:2482-8.

16. Ali NMA, Gameel, FEMH, Elsayid M, Babker AM. Alterations in D-Dimer, Prothrombin Time and Activated Partial Thromboplastin Time as Thrombogenesis Activity Markers in Patients with Acute Myocardial Infarction. Open Journal of Blood Diseases 2016; 6: 1-5.

17. Haseeb A, Khan, Abdullah S, Alhomida, Tamader Y, Al Rammah, Samia H, Sobki, Mohammad S, Ola, Adnan A Khan. PT and aPTT are significantly increased in AMI patients on anticoagulation. therapy.Epub 2013;297.

18. Ersan Tatli, Fatih Ozcelik, Meryem Aktoz . plasma fibrinogen level may predict critical coronary artery stenosis in young adults with myocardial infarction. Cardiology journal 2009; 319-320

19. Thomas AE, Green FR, Kelleher CH, Wilkes HC, Brennan PJ, MeadeTW, Humphries SE. Variation in the promoter region of the $\mathrm{b}$ fibrinogen gene is associated with plasma fibrinogen levels in smokers and in non-smokers. Thromb Haemost. 1991; 65:487-490.

20. ECAT Angina Pectoris Study Group. Baseline association of haemostatic factors with the extent of coronary risk factors in 3000 patients with angina pectoris undergoing coronary angiography. Eur Heart J 1993; 14: 8-17.

21. Engstrom G, Stavenow L, Hedblad B. Inflammationsensitiveplasma proteins, stroke. diabetes, and mortality and incidence of myocardial infarction and A population-based study. Diabetes 2003; 52: 442-447.

22. Jun Zhu, Xiaohua Su, Gang Li, Jingsong Chen, Bing Tang, Yongjian Yang. Weight and weight change and risk of acute myocardial infarction and heart failure - the HUNT Study. Arch Med Sci 2014; 10 (5): 855-862.

23. Schargrodsky H, Rozlosnik J, Ciruzzi M, et al. Body weight and nonfatal myocardial infarction in a case-control study from Argentina. Soz Praventivmed 1994; 39: 126-33. 